\section{The Aberfan disaster: 33-year follow-up of survivors}

\author{
LOUISE MORGAN, JANE SCOURFIELD, DAVID WILLIAMS, ANNE JASPER \\ and GLYN LEWIS
}

At 09.15 h on 21 October 1966, a coal slag heap collapsed on to a primary school in the mining village of Aberfan, South Wales, killing 116 children; 145 children survived. Subsequently a large proportion of the survivors suffered from sleeping difficulties, nervousness, lack of friends, unwillingness to go to school and enuresis. Lacey (1972) commented that 'it seems very likely that many of the Aberfan children may experience psychiatric problems in later life'.

Studies suggest that children can develop post-traumatic stress disorder (PTSD) and other psychological problems following traumatic events (e.g. Terr, 1983; McFarlane, 1987; Yule et al, 1990; Green et al, 1991, 1992; Bolton et al, 2000; Breslau et al, 2000). However, there is some controversy over the persistence of PTSD that started in childhood. The aim of this study was to examine the long-term psychological impact of the Aberfan disaster on the children (aged 4-11 years) who had attended the junior school, survived its engulfing and who were, at follow-up, adults in their late thirties and early forties.

\section{METHOD}

\section{Sample}

A register of 145 survivors from the primary school, aged 4-11 years at the time of the disaster, was compiled using the admission records of the Afon Taf comprehensive school in Aberfan, which almost all of the survivors subsequently attended. Of those survivors, 115 were traced to their current addresses with the help of the Bro Taf Family Health Services Authority and current general practitioners. The latter forwarded a letter requesting an interview to the survivors. Those giving consent to participate were interviewed in their homes, places of work or a clinical setting. The comparison group consisted of 379 persons who attended the same secondary school but different junior schools: 326 were traced in the same way as the survivors. This group was chosen to be as similar as possible to those living in Aberfan. It was intended to obtain a ratio of 2 comparisons to 1 survivor in order to improve the statistical power of the study.

\section{Instruments}

All participants were interviewed using a computerised version of the Composite International Diagnostic Interview (CIDI; World Health Organization, 1997), a fully structured, standardised interview that generates ICD-10 diagnoses. Disorders were then grouped into depressive, anxiety and substance misuse disorders (World Health Organization, 1992). Depressive disorders included F32.0, F32.1, F32.10, F32.11, F32.2, F33.10, F33.11, F33.2 and F34.1. Anxiety disorders included F40.0, F40.00, F40.01, F40.1, F40.21, F40.22, F40.23, F40.24, F41.0, F41.01, F41.1 and F42.1. Substance misuse included F10.1, F10.2 and F11.2. The diagnostic code for PTSD was F43.1.

\section{Lifetime incidence of PTSD}

In the PTSD section of the CIDI, the survivors were questioned with specific reference to the Aberfan disaster. This section provides a diagnosis of lifetime PTSD; that is, whether participants have experienced PTSD as a direct result of the disaster at some time in their subsequent lives. The comparison group were asked which traumatic events, from a specific list, they had experienced in their lifetime. They were then questioned in relation to the one that they felt was the most traumatic of these experiences. Survivors were not asked about other traumatic experiences because the PTSD questions within the CIDI relate only to a single specific incident, and as the Aberfan disaster was the main focus of the study, it was decided to restrict questions to this incident.

\section{Current levels of PTSD}

To assess current PTSD levels, the survivors completed the 15-item Impact of Event Scale (Horowitz et al, 1979). A score of 35 or above on this scale was used to define a case. This threshold was chosen on the basis of an existing data-set that used the same measure. All participants also completed the 28-item General Health Questionnaire (GHQ), and questionnaire 
measures of current health and social satisfaction. A score of 5 or above on the GHQ was used to define a case (Goldberg $\&$ Hillier, 1979; Goldberg \& Williams, 1988). The interviews were carried out by experienced health care professionals and academically trained researchers.

\section{Analyses}

Odds ratios were calculated for all outcome measures, namely GHQ scores, PTSD, anxiety disorders, depressive disorders, substance misuse, and any psychopathological disorder. The risk of PTSD was then assessed taking into account the possible effects of gender, marital status, age, employment and education, using the Mantel-Haenszel method and performed using STATA 6 software. The MantelHaenszel method assesses relative risk and adjusts for the confounding effects of other variables (see Breslow \& Day, 1987).

\section{RESULTS}

\section{Response rate}

From a total of 145 survivors, 115 were traced and 41 agreed to take part in the study $(36 \% ; 28 \%$ of total). Of the 115 who were invited to take part, 25 declined, 1 had died and 48 did not reply. From 379 people identified as potential comparisons, 326 were traced and invited to take part: 72 agreed $(22 \% ; 19 \%$ of total), 85 declined, 5 had died and 163 did not reply.

\section{Demographic data}

Table 1 shows, for both survivor and comparison groups, the mean age at the time of the disaster and at follow-up, the range of time of follow-up after the disaster, the gender of the participants, marital status, education, current employment status and prevalence of unemployment. Although most of the variables are similar in the two groups, it is notable that the survivors achieved higher levels of education. Participants were also asked whether they had any difficulties in relationships with friends or relatives and whether they had any concerns about their children, either at home or at school. No significant difference emerged between the groups on these measures.

\section{Representativeness of the survivor group}

The majority of the survivors did not want to take part in the study, so it is important to know how representative our subgroup was. Unfortunately, definitive claims about the group's representativeness cannot be made. Ethical restrictions prevented us from obtaining any information about the survivors who had not consented to take part in the research. However, some of the survivors were seen by a psychiatrist after the disaster at the request of solicitors requiring medico-legal reports. As these records are now in the public domain, we were granted access to them. Of the 41 survivors who did agree to take part, $24(59 \%)$ had been referred to the psychiatrist (11 men, 13 women). Of the 74 who did not take part in the study, $28(38 \%)$ had been referred (13 men, 15 women) (odds ratio 2.22, 95\% CI 1.73-2.84).

\section{Lifetime psychopathology}

The survivors were more likely than the comparison group to have suffered from PTSD (Table 2): odds ratio 3.38, 95\% CI
1.40-8.17. The traumas suffered by the comparison group included witnessing someone being badly injured or killed $(20 \%)$, being seriously attacked or assaulted $(14 \%)$ and being involved in a fire, flood or other natural disaster $(14 \%)$. There was no statistically significant difference in the prevalence of anxiety disorders, depressive disorders or substance misuse disorders.

Table 3 shows the odds ratios for PTSD after adjustment for gender, marital status, age, current employment, 'ever unemployed' and level of education. After adjustment for gender, there was a slight reduction in the odds. However, after adjustment for marital status and education, there was a slight increase.

\section{Current psychiatric morbidity}

When assessed with the GHQ, $23 \%$ of the survivors $(95 \%$ CI $10-37)$ and $21 \%$ of the comparisons (95\% CI 12-30) were designated as cases. The odds ratio was 1.21 (95\% CI 0.45-3.22). This was not substantially altered after adjustment for confounding variables.

The data from the CIDI assessment showed that $25(61 \%)$ of the survivors

Table I Socio-demographic characteristics of participants

\begin{tabular}{|c|c|c|c|c|}
\hline & \multicolumn{2}{|c|}{ Survivors $(n=4 I)$} & \multicolumn{2}{|c|}{ Comparisons $(n=73)$} \\
\hline \multicolumn{5}{|l|}{ Age (years) } \\
\hline \multicolumn{5}{|l|}{ At disaster: } \\
\hline Mean (s.d.) & \multicolumn{2}{|c|}{$7.73(3.71)$} & \multicolumn{2}{|c|}{$7.98(3.54)$} \\
\hline Range & \multicolumn{2}{|c|}{$4-11$} & \multicolumn{2}{|c|}{$4-11$} \\
\hline \multicolumn{5}{|l|}{ At follow-up: } \\
\hline Mean (s.d.) & \multicolumn{2}{|c|}{$40.24(1.61)$} & \multicolumn{2}{|c|}{$40.67(1.66)$} \\
\hline Range & \multicolumn{2}{|c|}{$37-44$} & \multicolumn{2}{|c|}{$38-44$} \\
\hline Time of follow-up after disaster & \multicolumn{2}{|c|}{32 years $7 \mathrm{~m}$ to 34 years $1 \mathrm{~m}$} & \multicolumn{2}{|c|}{33 years $I \mathrm{~m}$ to 34 years $2 \mathrm{~m}$} \\
\hline Gender: male $n(\%)$ & 21 & $(5 I)$ & 24 & (33) \\
\hline \multicolumn{5}{|l|}{ Marital status: $n(\%)$} \\
\hline Married/cohabiting & 31 & $(76)$ & 52 & (7I) \\
\hline Single & 5 & $(12)$ & 9 & $(12)$ \\
\hline Divorced/separated/widowed & 5 & $(12)$ & 12 & (16) \\
\hline \multicolumn{5}{|l|}{ Education: $n(\%)$} \\
\hline Left school before O levels & 14 & (34) & 41 & $(56)$ \\
\hline O levels & 15 & $(37)$ & 20 & $(27)$ \\
\hline A levels & 3 & (7) & 2 & (3) \\
\hline Degree & 5 & $(12)$ & 9 & $(12)$ \\
\hline Higher degree & 4 & $(10)$ & I & (I) \\
\hline Currently employed: $n$ (\%) & 28 & $(68)$ & 50 & $(68)$ \\
\hline Ever unemployed: $n$ (\%) & 30 & (73) & 54 & (74) \\
\hline
\end{tabular}


had experienced at least one PTSD symptom in the preceding 2 weeks (13 men, 12 women) (95\% CI 12-38). The Impact of Event Scale revealed that $12(29 \%)$ of the survivors met diagnostic criteria for current PTSD (4 men, 8 women) (95\% CI 15-43). Table 4 shows a summary of more detailed information obtained from the latter scale: $54 \%$ reported that any reminder brought back feelings about the disaster and that pictures popped into their minds; $49 \%$ reported thinking about it without meaning to and experiencing strong feelings about it: $46 \%$ tried not to think about it, avoided talking about it and tried to remove it from their memories; and 34\% reported still experiencing bad dreams or difficulty sleeping due to intrusive thoughts about the disaster.

Table 2 Numbers, percentages and odds ratios for lifetime psychopathological disorder in the survivor and comparison groups

\begin{tabular}{|c|c|c|c|c|c|c|}
\hline \multirow[t]{2}{*}{ Diagnosis } & \multicolumn{2}{|c|}{ Survivors $(n=4 I)$} & \multicolumn{2}{|c|}{ Comparisons $(n=60)$} & \multirow[t]{2}{*}{ Odds ratio } & \multirow[t]{2}{*}{$95 \% \mathrm{Cl}$} \\
\hline & $n$ & $\%$ & $n$ & $\%$ & & \\
\hline PTSD & 19 & 46 & 12 & 20 & 3.38 & $1.40-8.17$ \\
\hline Any anxiety disorder & 25 & 61 & 33 & 55 & 1.28 & $0.57-2.87$ \\
\hline Any depressive disorder & 19 & 46 & 21 & 35 & 1.60 & $0.71-3.61$ \\
\hline Any substance misuse & 2 & 5 & 8 & 13 & 0.33 & $0.07-1.66$ \\
\hline $\begin{array}{l}\text { Any psychopathological disorder, } \\
\text { including PTSD }\end{array}$ & 34 & 83 & 46 & 77 & 0.94 & $0.37-2.39$ \\
\hline
\end{tabular}

PTSD, post-traumatic stress disorder.

Table 3 Odds ratios for lifetime post-traumatic stress disorder (PTSD) between the survivor and the comparison groups with adjustments for possible confounders

\begin{tabular}{lccc}
\hline & Odds ratio & Adjusted odds & $95 \% \mathrm{Cl}$ \\
\hline Risk of PTSD & 3.38 & & $1.40-8.17$ \\
Gender & & 2.97 & $1.21-7.24$ \\
Marital status & 4.12 & $1.59-10.63$ \\
Age & 3.30 & $1.36-7.99$ \\
Current employment & 3.29 & $1.35-7.99$ \\
Ever been unemployed & 3.37 & $1.38-8.20$ \\
Level of education & 4.41 & $1.58-12.28$ \\
\hline
\end{tabular}

\section{DISCUSSION}

\section{Lifetime incidence of PTSD}

Half the survivors of the Aberfan disaster were found to have had PTSD at some time in their lives, suggesting that trauma experienced in childhood can lead to the onset of PTSD. This finding supports some previous studies (e.g. Terr, 1983; McFarlane, 1987; Yule et al, 2000) and contradicts others (e.g. Green et al, 1994), although it should be noted that different studies have used different diagnostic instruments. When compared with a group of people from a nearby village, the odds of survivors developing PTSD was 3.38 (95\% CI 1.40-8.17).

\section{Affective disorders}

Previous research suggests that affective disorders are almost as common a response to trauma as is PTSD. In our study there was no significantly increased risk in the survivor group of suffering from psychiatric disorders other than PTSD. High levels of psychopathological disorder, including PTSD, were observed in the comparison group. This should be interpreted with caution. It could indicate a response bias, in that the people who agreed to participate in the research were those who were more likely to experience psychological problems. This is supported by the large number of survivors in the research group who had been referred to a psychiatrist after the disaster. The 1998 Welsh Health Survey (National Assembly for Wales, 1999) also found the highest prevalence of psychiatric disorder in the economically deprived industrial valleys of South Wales, an area in which all participants lived.

Table 4 The Impact of Event Scale: symptoms of post-traumatic stress disorder in the survivor group $(n=4 I)$ experienced in the few days preceding the interview

\begin{tabular}{|c|c|c|}
\hline Symptom & $\begin{array}{l}\text { Proportion giving a positive } \\
\text { response (\%) }\end{array}$ & $95 \% \mathrm{Cl}$ \\
\hline Pictures about it popped into my mind/any reminder brought back feelings about it & 54 & $39-69$ \\
\hline I thought about it when I didn't mean to/I had waves of strong feeling about it & 49 & $34-64$ \\
\hline Other things kept making me think about it/I have tried not to think about it & 46 & $31-61$ \\
\hline $\begin{array}{l}\text { I avoided letting myself get upset when I thought about it or was reminded of it/I was aware that I still had } \\
\text { a lot of feelings about it but I didn't deal with them }\end{array}$ & 44 & $29-59$ \\
\hline I have tried not to talk about it & 37 & $22-52$ \\
\hline I tried to remove it from my memory & 34 & 20-48 \\
\hline I had trouble falling/staying asleep as pictures/thoughts about it came into my mind/I had dreams about it & 34 & $20-48$ \\
\hline My feelings about it have been sort of numb/l have felt as if it hadn't happened or wasn't real & 32 & $18-46$ \\
\hline I have stayed away from reminders of it & 24 & $11-37$ \\
\hline
\end{tabular}


Alternatively, this finding could indicate a ceiling effect. As baseline rates for psychopathological disorders were so high in this study, it could simply be that developing PTSD does not raise these rates any higher.

\section{Current PTSD}

Yule et al's (2000) conclusion that PTSD symptoms can persist into adult life is also supported here, as this study found that 12 (29\%; $95 \%$ CI $15-43)$ of the survivors met diagnostic criteria at follow-up. For many, the disaster still evoked intense feelings, intrusive thoughts and efforts to avoid thinking or talking about it - all key components of PTSD. This suggests that even 33 years after the disaster the intensity of experience, characteristic of PTSD, was still very much present in many of their lives.

\section{Limitations}

The response rates in the study are low, but this is understandable given that the disaster had happened 33 years before. The comparison group members were chosen to be as similar as possible to the survivors and the non-response bias may well be similar in both groups. It seems that low response rates are characteristic of this type of research. Yule's study of survivors of the sinking of the cruise ship Jupiter (Yule et al, 1990) involved just 25 of the 217 children only 5-8 years after the disaster. The follow-up of survivors of the Buffalo Creek dam collapse (Green $e t a l, 1991$ ) included 193 out of 207 survivors. Three years later this number had dropped to 99 (Green et al, 1994).

Previous research suggests that people living near to the scene of disasters and other traumatic events may also show signs of PTSD. The comparison group came from a nearby village and attended the same secondary school as the survivors. This is the main strength of the design, and if anything the increased risk among the survivors of PTSD may be an underestimate, given the proximity to the disaster.

Given the essentially retrospective nature of this type of research, the years that have passed may be obscuring our understanding of what has happened to the people over the course of their lives, and with this sample the true extent of the experience may never be known. The disaster still undoubtedly affects the people of Aberfan in ways poorly recorded by diagnoses and standardised assessments. A

\section{CLINICAL IMPLICATIONS}

Children are affected by traumatic events in a similar way to adults.

- Children are not necessarily more adaptable and malleable than adults.

- In many cases, post-traumatic stress disorder permits throughout life.

\section{LIMITATIONS}

- Low response rates.

- The comparison group was closely involved in the disaster and its repercussions.

- The retrospective design might have observed participants' memories of life events.

LOUISE MORGAN, PhD, JANE SCOURFIELD, MRCPsych, Department of Psychological Medicine, University of Wales College of Medicine, Cardiff; DAVID WILLIAMS, MRCPsych, St Cadoc's Hospital, Caerleon, Newport; ANNE JASPER, MRCPsych, Raeside Clinic, Birmingham; GLYN LEWIS, MRCPsych, Department of Psychological Medicine, University of Wales College of Medicine, Cardiff, UK

Correspondence: Louise Morgan, Department of Psychiatry and Behavioural Sciences, Royal Free Hospital, Pond Street, Hampstead, London NW3 IYD, UK. E-mail: L.Morgan@rfc.ucl.ac.uk

(First received 29 July 2002, final revision 26 November 2002, accepted 9 December 2002)

few of the survivors talked about the fear evoked at the sound of a lorry passing their house, or of an aircraft flying overhead. Intense memories of the disaster are aroused by the slightest noise or smell. A number of the survivors now have children the age that they were at the time of the disaster. This seems to arouse new feelings, as they are now able to see the disaster from their parents' perspective. Many are reluctant to let their children leave the house when the weather is bad, as they are reminded of the appalling weather preceding the disaster.

\section{The future}

Experiencing trauma in childhood is not substantially different from experiencing trauma in adulthood, in terms of the subsequent development of PTSD. It does not appear that children are more adaptable and malleable than adults in the face of adversity; rather, they respond in similar ways, and traumatic events in childhood can have effects on psychological health that persist for many years. These findings have important implications for the ways in which children and young people are treated following a traumatic event. In cases of adults with PTSD full remission is usually attainable (Connor et al, 1999; Hembree \& Foa, 2000); we have no reason to assume that this will be different with younger populations.

\section{ACKNOWLEDGEMENTS}

We thank the Wales Office for Research and Development in Health and Social Care for funding this research, and the people of Aberfan who so generously gave up their time to participate in the study. We also thank Truda Bell and Dietmar Hank for their help with interviewing participants.

\section{REFERENCES}

Bolton, D., O'Ryan, D., Udwin, O., et al (2000) The long term psychological effects of a disaster experienced in adolescence. II: General psychopathology. Journal of Child Psychology and Psychiatry, 41, 513-523.

Breslau, N., Davis, G. C., Peterson, E. L., et al (2000) A second look at comorbidity in victims of trauma: the posttraumatic stress disorder-major depression connection. Biological Psychiatry, 48, 902-909.

Breslow, N. E. \& Day, N. E. (1987) Statistical Methods in Cancer Research. Vol. 2. The Design and Analysis of Cohort Studies. Lyon: IARC.

Connor, K. M., Sutherland, S. M., Tupler, L. A., et al (1999) Fluoxetine in post-traumatic stress disorder. Randomised, double-blind study. British Journal of Psychiatry, 175, 17-22. 
Goldberg, D. P. \& Hillier, V. F. (1979) A scaled version of the General Health Questionnaire. Psychological Medicine, 9, 139-145.

— \& Williams, P. (1988) The User's Guide to the GHQ Windsor: NFER-Nelson

Green, B. L., Korol, M., Grace, M. C., et al (1991)

Children and disaster: age, gender, and parental effects on PTSD symptoms. Journal of the American Academy of Psychiatry, 30, 945-51.

_ , Lindy, J. D., Grace, M. C., et al (1992) Chronic posttraumatic stress disorder and diagnostic

comorbidity in a disaster sample. Journal of Nervous and Mental Disease, 180, 760-776.

_, Grace, M. C., Vary, M. G., et al (1994) Children of disaster in the second decade: a 17 year follow up of Buffalo Creek survivors. Journal of the American Academy of Child and Adolescent Psychiatry, 33, 7I-79.
Hembree, E. A. \& Foa, E. B. (2000) Posttraumatic stress disorder: psychological factors and psychosocial interventions. Journal of Clinical Psychiatry, 6I (suppl. 7) S33-S39.

Horowitz, M., Wilner, N. \& Alvarez, W. (1979) Impact of Event Scale: a measure of subjective areas.

Psychosomatic Medicine, 4I, 209-218.

Lacey, G. N. (1972) Observations on Aberfan. Journal of Psychosomatic Research, 16, 257-260.

McFarlane, A. C. (1987) Posttraumatic phenomena in a longitudinal study of children following a natural disaster Journal of the American Academy of Child and Adolescent Psychiatry, 26, 764-769.

National Assembly for Wales (1999) Welsh Health Survey 1998. Cardiff: Government Statistical Service.
Terr, L. C. (1983) Chowchilla revisited: the effects of psychic trauma four years after a school-bus kidnapping. American Journal of Psychiatry, 140, 1543-1550.

World Health Organization (1992) The ICD-10 Classification of Mental and Behavioural Disorders. Geneva: WHO

- (1997) Composite International Diagnostic Interview (CIDI-AUTO): Version 2.I. Geneva: WHO.

Yule, W., Udwin, O. \& Murdoch, K. (1990) The Jupiter sinking: effects on children's fears, depression and anxiety. Journal of Child Psychology and Psychiatry, 31 |05|-|06|.

_, Bolton, D., Udwin, O., et al (2000) The long term psychological effects of a disaster experienced in adolescence. I: The incidence and course of PTSD. Journal of Psychosomatic Research, 4I, 503-5II. 